\title{
Teología de la liberación y teología oriental. Una aproximación
}

\author{
VICTOR CODINA \\ Centro de Investigación y Servicio Popular (CISEP) \\ Oruro. Bolivia.
}

\section{Videtur quot non..... sed contra}

Aparentemente nada más audaz y descabellado que el intentar una aproximación entre la teologia de la liberación latinoamericana (TL) y la teologia de la tradición cristiana oriental (TO). A prinera vista sus lineas de fondo parecen claramente divergentes. Mientras a la TL se le acusa de horizontalismo, de peligro de reduccionismo socio-politico, de inmanentismo, de influjos marxistas y de poca sensibilidad para las dimensiones graluitas de la fe, la TO es tradicionalmente una teologia de la trascendencia, del misterio, de la divinización, la liturgia y la escatologia. Mientras la Tl. insiste en el Jesús histórico, la TO recaica fuercementc la divinidad del Logos encarnado, incluso con riesgo de monofisismo. Mientras la TL habla de una Iglesia comprometida en la lucha por la justicia, la TO contempla una Iglesia sacramental y eucaristica que anticipa litúrgicamente la Jerusalèn celestial. La lista de contrastes podría proseguir lodavia más.

Añadamos a estas diferencias de orientación teológica, los diversos trasfondos culturales e históricos en que se han desarrollado ambas leologias. La TO nace en el suelo del oriente cristiano, enlazado con los origenes del mismo evangelio. En ella se mezclan culluras semilicas, griegas, sirias, alejandrinas. antioqueñas, bizantinas, árabes, eslavas, rusas... y se desarrollan, desde el comienzo del cristianismo hasta nuestrus dias, dentro de una gran pluralidad de épocas históricas y con una dolorosa ruptura con la Iglesia latina a partir del siglo XI. La TL es moderna, nacc en América Latina, dentro del mundo católico occidental, y de alguna forma puede ser considerada como la punta de lanza de la leologia contcmporánea. También la problemática que mueve a ambas teologias es diferente. Mientras la TL se preocupa por la injusticia de América Latina, la TO parece interesarse sobre todo por la parusia. Parece, pues que la TL cs tan diferente de la TO como el resto de la teología occidental, de la cual forma parte; o, incluso, lodavía más diferente. 
Sin embargo, las divergencias quizás no son tan radicales como pudiera creerse. De hecho, ambas teologias resultan un poco sorprendentes para el occidente tipicamente latino, y algunas de las acusaciones que hoy se lanzan contra la TL recuerdan las viejas controversias entre la teologia latina y la bizantina, aunque traten temas diferentes $I$

Las críticas que la TO suele hacer a la teologia latina clásica -racionalismo, individualismo, escncialismo abstracto, mundanización, optimismo respecto a la historia y al proceso-corresponden a las que la TL laace a la tcologia moderna del primer mundo, que se ha quedado anclada ch) el dialogo con la primera llustración. El llamado Primer nundo es tipicamente occidental, nacido de las raices de la cristiandad medieval y de la Reforma. Al margen de este mundo secular, de progreso y de técnica, quedó hasta hace poco el mundo oriental y el tercer mundo de hoy, fruto del desarrollo imarginador del primer mundo. La TO mantiene unidas una scric de dimensiones que en la teologia latina se escindicron (teologia y espiritualidad, religiosidad oficial y popular, jerarquia y pueblo) y que hoy dia en la TL se vuelven a integrar. La misma problemática de la Reforma protestante, tipicamente occidental, desconocida por la Iglesia del oriente y trasladada lucgo a América Latina, halla hoy en la TL un acercamiento sorprendente, hasta tal punto que se puede decir que la TL cs realmente ecuménica. Podemos concluir que tanto la TO como la TL tienen un carácter marginal respecto a la teologia del primer mundo: una corresponde, en gran parte, al segundo mundo hoy socialista, la otra al tercer mundo que busca caminos para librarse del capilalismo occidental. Las relaciones entre la TL y la TO no son tan superficiales como pudiera parecer. La aproximación entre ambas merece profundizarse. No se trata de buscar paralelismos artificiales, sino convergencias e incluso complementariedad.

Cuando hablamos de TL nos referimos concretamente al movimiento teológico surgido en América Latina desde fines de los años sesenta, que a pesar de sus diversos acentos y tendencias, mantiene una unidad teológica. ${ }^{2}$ Cuando hablamos de TO estamos pensando en la teología surgida en el oriente cristiano y que es común a la Iglesia católica oriental y a la Iglesia de la ortodoxia, aunque cntre ambas iglesias haya difcrencias dogmáticas. No nos interesa aqui discutir los problemas dogmáticos que separan a la Iglesia ortodoxa de la católica, sino que nos limitamos a los aspectos especificamente teológicos que la diferencian de la Iglesia latina, y que durante siglos fueron compatibles con una misma unidad de le y de comunión, mostrando así cómo la unidad de fe se puede vivir desde teologias diferentes. La TO es tan rica y tiene una historia tan larga que sicmpre resulta arriesgado el inlentar dibujar cuáles son sus líneas maestras. Sin embargo, los mismos autores orientales nos ofrecen valiosas síntesis de la TO que podemos utilizar como malerial básico para nuestra tarea de aproximación entre la TL y la TO. ${ }^{3}$

\section{Método}

La TO considera la teología como vida, nace de la vida y se orienta a la vida. Parte del supuesto de que la revelación no se nos dio para nuestra curiosi- 
dad intelectual, sino para nuestra salvación. Las luchas dogmáticas sostenidas por la Iglesia de oriente en los primeros siglos no tienen una orientación meramente teórica o especulativa, sino vilal y práctica. Si deliende la idea de la divinización contra los gnósticos, o que el Verbo es consubstancial al Padre contra los arrianos, o la unidad personal de Cristo contra los apolinaristas, monofisitas, o monoleletas... todo ello se ordena a posibilitar la divinización del crisliano, la posibilidad de participar por Cristo de la vida divina de Dios: si el Verbo no es Dios, o si Cristo no es verdadero Dios y plenamente hombre, no nos puede comunicar la vida de Dios a los hombres. Ia misma divinidad del Espiritu se prueba a partir de la vida nueva del cristiano: si tenemos una vida divina, el Espiritu, su origen, no puede ser sino Dios.

Y por otra parte la tcologia debe vivilicar la vida. Los dogmas no nos pertenecen, sino ell la medida en que los vivimos, aljima Filarelo de Moscú ${ }^{4}$ y "una teología sin acción es la teología de los demonios" repite Máximo Con Tesor. La división tan típicamente occidemial entre una teología recta (ortodoxia) y una praxis deficiente o nula es desconocida por el orientc. Sin praxis no hay teologia ni fe auténtica. Sin ortopraxis no hay ortodoxia. Teologia y vida se unen. No hay divorcio entre teologia y espiritualidad.

Para que la teología sea auténtica se necesita una ruptura lógica: la razón debe ser salvada para no emborracharse por la unidimensionalidad racional y no quedar cautiva por la idolatría de los conceptos: "los conceptos crean idolos, sólo la admiración capıa algo," repite Gregorio de Nisa.'

Es una teología más sapiencial que lógico-discursiva, y aunque use de mediaciones filosóficas para expresar el contenido de la fe, nunca picrde el sentido admirativo.

Su apertura al misterio de Dios y sıı sentido religioso se ıraducen en el método llamado "apofático" típico de la teología negativa: ante el misterio de Dios es más lo que desconocemos que lo que sabemos, llegamos más por la adoración, el silencio y la invocación, que por la lógica. La palabra "Dios" es siempre un vocativo para el oriente. Este misterio de Dios, indecible, no es sólo lípico del Antiguo Testamento, de Moisés que conlempla a Dios en la oscuridad de la nube según el comentario de Gregorio de Nisa, ${ }^{6}$ sino tambièn es propio del Nuevo Testamento. Más aún, aqui se revela de forma patente la Cilantropia de Dios, "el amor loco de Dios" (N. Cabásilas, P. Evdokimov) que llega hasta el escándalo de la cruz y hasta el misterio del Cordero degollado desde la creación del nuundo (Ap. 5,6). De ahi el carácter antinómico de la TO: el misterio de Dios y su obra son una paradoja, cruz para la razón nalural, sólo inteligible desde la fe y accesible a través de los "simbolos" o "sacramentos:" la escritura, la liturgia, los iconos, la Iglesia, el misterio del hombre. La lejania del misterio de Dios se vuelve cercania en las realidades de este mundo que son sacramento de su presencia: "la gloria de Dios es la vida del hombre," dirá Ireneo.

Otro aspecto interesante del método teológico oriental es el carácter colegial de la teologia: la teologia nunca es algo meramente individual, sino que brota de la comunión con la tradición eclesial y con la comunidad de fe. ${ }^{7}$ La 
comunidad es el sujeto de la leología y el leólogo no hace más que expresar esta fe colegial ell conexión con cl pueblo de Dios. Algunos de los grandes tcólogos de la TO han sido laicos (Origenes, Cabásilas, Evdokimov, Clémenı...).

Si vamos ahora a la TL es evidente que hallamos punlos comunes con el método de la TO hasta ahora expuesto. Es una tcología desde la praxis que quiere responder a una experiencia vital de los cristianos cn su lucha por la liberación y que se orienta no solo a la ortodoxia, sino a la praxis correcta (ortopraxis). Es una teología que nace de una espiritualidad y (jue no sc explica sin una profunda experiencia cspiritual. Antes de ser reflexiva es contemplativa y silenciosa, ${ }^{9}$ en una mezcla de admiración y de indignación, porque la vida de Dios se experimenta con muerte en muchos hermanos.

Si bien la TI. no sucle usar el lenguaje de divinización del cristiano, sino el de liberación y humanización, sin embargo la lógica de su pensamiento es semejante a la TO: Dios quiere que el hombre sca hombre, es decir, imagen de Dios, y puede rellejar en él la gloria de Dios. Sobre todo el pobre alcbe poder ser de nuevo imagen de Dios. Como se sabe, Monseñor Romero adapló cl "la gloria de Dios es la vida del hombre" en "la gloria de Dios es la vida del pobre." 10 La vida del Dios de la vida se debe poder comunicar plenamente a todos los hombres, desde la mediación primera de la vida - el pan- hasta la plenitud de la vida divina. ${ }^{11}$

La TL es muy consciente del carácler paradójico y misterioso de la fe y del evangelio, rechazando toda acomodación burguesa de la fe: Dios sc pone al lado de los pobres, les hace justicia, se encarna en kénosis total, Jesús evangeliza a los pobres y se identifica con ellos, la Iglesia opta por los pobres y confiesa que ellos poseen un potencial evangelizador. La locura de la cruz subvierte la lógica humana del poder y del dinero. El pobre se convierte en sacramento de Dios, de modo que sólo desde la opción por él y la solidaridad con él la teología puede ser cristiana. I.a ruplura epistemológica de la TL, expresada en esta solidaridad con los pobres, formula de forma radical la necesidad de la conversión de la razón que también la TO postula: la razón ha de ser evangelizada para poder hacer teologia y evangelizada precisamente por los pobres. ${ }^{12}$

Finalmente el tema de la teologia colegial halla su expresión en la dimensión comunitaria y popular de la TL, ligada a las comunidades eclesiales de base. El sujeto fundamental es el pueblo, del cual el teólogo es servidor. El teólogo no es un simple intelectual, ni tan sólo un "intelectual orgánico," sino ante todo un creyente que acompaña con su reflexión cristiana al caminar del pueblo de Dios.

No se trata de querer ver paralelismos matemáticos, ni caer en forzados calcos metodológicos. Pero es indudable que hay mayor sintonia y proximidad entre el método de la TL y de la TO, que entre la TL y el método más racionalista de la tradición occidental que se ha mantenido en la teologia del primer mundo y que con la apertura a la modernidad secular todavia se ha agudizado más. Tanto la TO como la TL poseen una visión más vitalista y real que jurídica y abstracta, más ontológica que esencialista y moral, más comunitaria que individualista, más espiritual que racionalista, más bíblica que escolástica. 
La profundización biblica de los diversos sentidos de la escritura, lipicamente patristica y del cristianismo medieval primitivo, "3 halla su correlato en la leclura bíblica de la TL. A los cuatro sentidos tradicionales de la TO (lisisuria. alegoría, tropologia, anagogia) corresponden el pre-texto, texio y con-texto de la lectura biblica de la TL. if Desde ángulos y siutuciones diferentes ambos merodos tienden a no limitar la escritura a la pura exégesis del lexto, sino a situarlo en la historia y en la comunidad eclesial de le. En la TL esta exégesis posee una clara dimensión popular.

Por or ra parte la dimensión simbólica, lipica de la IO. puede enricueccer a la TL $y$ hacerle profundizar algunas imuiciones que se ha formulado, por ejemplo con respecio a la religjosidad popular. Miemras la TO mamuvo siempre la importancia del simbolo, la tcologia latina occidental en la alta edad media paso "Jel simbolo a la dialécica," "Is introduciendo las categorias aristotélicas (causa, substancia, accidente, género. especie) las cuales están en la base de la teología cicntifica y que hoy constatamos que han asfixiado muchos aspectos de la fe cristiana. La religiosidad popular del mundo occidental adqujere pujanza precisamente en este momento de pérdida del símbolo y se ha convertido hasta hoy en la mayor reserva simbólica de la Iglcsia latina. Una mayor atención a lo simbólico en la TL la acercaria al pueblo y a su religiosidad. 16

\section{Antropología}

Aunque tal vez la TO no elabore una antropologia sistemática en el sentido moderno, sin embargo, en toda su rellexión existe un discurso implícito sobre el hombre. A la voz de los teólogos se une la voz de los ascelas y místicos, quienes con su ciencia experimental nos descubren los misterios del hombre, tanto sus éxtasis como los abismos de perversión que el hombre puede encerrar.

Su antropologia se centra en el tema de la imagen de Dios de inspiración profundamente biblica $(\mathrm{Gn}, 1,26-27)$, aunque ellos aprovechan elementos del platonismo para explicarlo. Con mayor precision afirma que el hombre es creado "según la imagen"' (Kat' eikóna), ya que la auténtica imagen del Dios invisible es Cristo, por quien todo ha sido hecho (Col. 1, 15-16; Jn. 1,3). El hombre es un lugar leológico, un misterio que participa de la dignidad del mismo Dios. La antropología oriental es irinitaria y apofática. La teologia de la imagen confiere a la TO la posibilidad de superar el dualismo tipicamente occidental entre naturaleza y gracia, o entre natural y sobrenatural. La naturaleza no es la "natura pura," porque desde su origen participa de la divinidad de la que es imagen, y a cuya semejanza tiende. El pecado siempre es algo "extranjero" a la naturaleza humana, la conversión es siempre "según la naturaleza."

El hombre se orienta a la divinización, la participación de la naturaleza divina $(2 \mathrm{Pe} .1,4)$ : "el hombre es una creatura que ha recibido la orden de llegar a ser como Dios" afirma Basilio, ${ }^{17}$ y "Dios se hace hombre para que el hombre se haga Dios," escribe Ireneo. ${ }^{18}$ Los teólogos del oriente contraponen esta vi- 
sión más ontológica a la concepción latina más intelectual de la visión beatifica.

En esta divinización del hombre se incluye tambièn a todo el cosınos, ya que la creación es la mansión del hombic. El "Teomaterialisıno" del que a veces la sido acusada la $\mathrm{rO}$, no es más que la serieclad con que se incluye a toda la creación en esle dinamismo que va del Génesis al Apocalipsis, del Alla al Omega (Ap. 22, 1-2).

Por olra parte, la dimensión personal del hombre no es para la TO individual, sino comunitaria, ya que cura en commion con la comunidad unitaria y con la comunidad humana. l.os leólogos rusos modernos insisten mucluo en esta dimensión integral y supraindividual de la conciencia humana, en csta espccie de comunidad y calolicidad humana (Sobornost), en un personalismo comunitario (Berdiaev Troubeiskoï), en la consubstancialidad con todos los hombres para el bien y para el mal, en la dimensión colecliva de la salud, comunión solidaria de todos en el "pléroma" paulino. F'cdorov llcga a exclamar: "el dogma de la trinidad es nuestro programa social," 19 indicando que la trinidad procede la raiz más profunda de la solidaridad social entre los hombres.

Pero esta misión dinámica y comunitaria del hombre y de la humanidad es también profundamente realista. Sin caer en el pesimismo lutcrano, la TO cs menos optimista sobre el hombre y su progreso que la teologia latina occidental, sobre todo la leologia progresista y liberal moderna. Existe un gran realismo sobre el mal y el pecado, realidad diabólica que se ha introducido en el mundo. El pecado produce una desintegración del hombre y del cosmos, un estado contra naturom, que culmina en la muerte. El pecado es algo real, una enfermedad de la naturaleza y del cosmos, asfixia ontológica, un parásito que anida en el hombre, una esclavitud, una contaminación, un abrir las puertas al infierno. Se necesitará la venida del scgundo Adán para liberar a la humanidad de esta tragedia real. La encarnación de Cristo no se limita a una reconciliación juridica, sino que es una liberación terapéutica del pecado y de sus consecuencias. Las energías divinas transforman la muerte en vida.

Por otra parte, la TO acentúa fuertemente la conexión pecado y muerte, hasta tal punto que ve en la muerte la consecuencia del primer pecado de la humanidad y el instrumento de transmisión y de solidaridad en el pecado. El pecado genera una desintegración y enfermedad mortal en toda la creación que contagia al hombre desde su nacimiento y lo debilita frente a la vida de Dios.

Mientas Agustin traduce Romanos 5,12 por "en quién todos pecaron" (visión hereditaria del pecado de Adán) y la moderna exégesis recalca la dimcnsión personal del pecado original, "puesto que todos pecaron" (Biblia de Jerusalén), la TO traduce "por la muerte todos pecaron." 20 Mientras occidente insiste en las dimensiones juridicas y morales del pecado original, la TO recalca el aspecto fisico-ontológico del pecado, que coloca a nuestra libertad en una situación de pecado, que estaria cerca de lo que la TL llama, "estructuras de pecado."

Este realismo sobre el mal y el pecado lleva a Soljenitsyn a exclamar: "la 
injusticia es más fuerte que nosotros, ha existido en el pasado y continuará er el fuluro." 21

La salvación es, pues, una liberación de la muerle, del pecado y el infierno personal y comunitario. Sólo Cristo nos puede liberar del pecado. Pero es preciso cooperat en esta salvación. La TO no ha intentado resolver metafisicamente el problema entre la gracia y la libertad, sino que agarra los dos exiremos de la cadcna: sólo Dios salva, el hombre debe cooperar a su sal、ación. I a memalidad lanina läcilmentc tiende a acusar de pelagianismo o semipelagianismo el "sinergismo" de la " $\mathrm{TO}$, el cual sólo desca cvilar el engaño cle esperar pasivamente la calvilción. La antropologia de la TO desemboca en una praxis. Más tarde volveremos sobre el mismo tema al tratar cle la espiritualidad.

Si dirigimos ahora los ojos a la TI. observaremos notables frutos de convergencia: la dignidad de la persona humana radica en ser creatura de Dios, imagen de Ćristo, destimacla a la vida plena; cl apofatismo de lodo hombre, sobre todo del pobre, en el cual se percibe la transcendencia de Dios; 22 la visión unitaria de la historia de salvación, la cual no se divide en historia profana e historia sagrada, sino en una historia que lo lleva a la vida o conduce a la muerte; ${ }^{23}$ la dimensión comunitaria del hombre, del cosmos y de la salvación; el realismo del pecado que desintegra al hombre y lo reduce a no-hombre; la relación pecado-muerte que la TL enlaza con el culto a los dioses de la muerte; 24 la dimensión global y estruclural del pecado, el cual cristaliza en estructuras injustas y asesinas, fruto del pecado y ocasión de nuevos pecados; la exigcncia de una liberación integral, que salve a la humanidad del infierno histórico donde está sumida; la exigencia de cooperación activa en la tarea liberadora y salvífica; el difícil camino que debe evitar tanto el pesimismo de la resignación como el pelagianismo milenarista. ${ }^{25}$ En fin, la orientación a la vida plena, que corresponde a la dinámica de la divinización.

La TO puede aportar a la TL notables enriquecimientos, tanto en torno al pecado, el mal y la muerte, como sobre la dimensión comunitaria del hombre, del cosmos y de la salvación. La TL historiza más el mal y el pecado en nuestro mundo, y en concreto en América Latina, en conexión con la pobreza y la injusticia. Pero ambas teologias poseen un pathos común.

\section{Cristología}

Para la TO la misión del Hijo y la misión del Espiritu Santo forman lo que ellos llaman la economia, es decir, la acción de Dios ad extra, mientras que la contemplación de la trinidad ad intra constituye la reologla. El Hijo y el Espiritu son "las dos manos del Padre" en expresión de Ireneo. Como luego veremos, entre estas dos misiones hay una inseparable complementariedad.

La cristología de la TO se orienta a la divinización del hombre: "Dios se encarna para que el hombre llegue a ser Dios." Esta divinización de hecho es salvífica, aunque a los orientales no les agrada el oh felix culpa agustiniano. La verdadera causa de la salvación es la filantropía divina. Esta dimensión 
salvífica de la cristología consiste en la liberación de la muerte, que es lo opuesto a la vida de Dios. La encarnación culmina, pues, en la salvación, salvación que se halla ya radicalmente en la misma encarnación. Esta salvación es vista más como curación o restauración que como rescate o salisfacción. El oriente cristiano posee una visión más ontológica y terapéutica de la salvación que juridica. Pero para sanar la naturaleza humana el Verbo debia asumirla: "lo que no es asumido, no puede ser deificado." 26 La encarnación es ya la raiz de la salvación y su fiesta litúrgica es llamada "la fiesta de la raiz."

Por esto, como ya vimos, las controversias cristológicas de los primeros siglos no eran discusiones puramente especulativas, sino la condición de posibilidad de una radical transformación de la humanidad en Cristo. Pero esta encarnación es kenótica, se realiza en forma de aniquilación, humillación, sometimiento, obediencia, pobreza, conforme a Filipenses 2,6-11. Estc punto es muy subiayado por la teología rusa: Cristo es el Cristo pobre, el humillado, el Hermano humilde de los humillados, de los pobres, de los enfermos, de los que sufren. ${ }^{27}$ La consubstancialidad de Cristo con la naturaleza humana lo licva a asumir la pobreza y la debilidad. La transfiguración de Cristo tan venerada en oriente, es una confesión de la divinidad de Cristo, cuyo resplandor por unos momentos anticipa ya la gloria de la resurrección.

La culminación de esta kénosis es la muerte en cruz. Más aún, la kénosis de Cristo se consuma en el descenso a los infiernos. Cristo baja a la ciudadela de la muerte para rescatar a la humanidad aprisionada por los lazos del Hades. Los iconos orientales muestran a Cristo glorioso saliendo del infierno, mientras agarra con sus manos a Adán y a Eva, primicias de la nueva humanidad. Es la vida que vence a la muerte.

La liturgia de la vigilia pascual expresa esta victoria golpeando con la cruz las puertas cerradas y oscuras del templo. Y Juan Crisóstomo canta en su homilia:

¿Dónde esta tu agujión, oh muerte?

Infierno ¿dónde está tu victoria?

Cristo ha resucitado y tú has sido arrasado.

Cristo ha resucitado y los demonios han caido.

Cristo ha resucitado y los ángeles se regocijan.

Cristo ha resucitado y la vida triunfa.

Cristo ha resucitado y ya no hay muertos en las tumbas

Porque Cristo constituye las primicias de los que duermen, habiendo resucitado de entre los muertos. ${ }^{28}$

La resurrección es el triunfo sobre el pecado y la muerte. El mensaje pascual cristiano es que la muerte fue vencida por Dios mismo, el cual al asumirla la ha derrotado. El gran error de fe para TO no es el ateismo, sino el negar la resurrección de Cristo. Esta resurrección posibilita la vida nueva en el cristiano. El cristiano no está llamado a la imitación de Cristo, sino a la vida en Cristo, que es el inicio del reino.

Dentro de la cristologia oriental coexisten dos corrientes, la alejandrina más mistica y la antioqueña, más centrada en el Jesús histórico. Pero aun la 
corriente alejandrina, a la cual occidente suele acusar de poco interés por el mundo y de criplomonofisismo, adınite la ignorancia de Cristo, su progreso en la ciencia, rechaza la incorruptibilidad de la humanidad de Jesús (frente al a $\int$ tardocetismo de Julián de Halicarnaso) y el error iconoclasta de que no se pueda describir picıóricamente a Jesús (agrapıodocetismo).

Finalmente digamos que la TO resalta la figura de María, ya que ella resume toda la historia de la economía divina en el mundo, como dice Damasceno. La Theolokos, jamás sin mancha, ha sido santificada por una larga purificación del Espiriutu en rodo el Antiguo Tesiamento, hasta hacerla morada digna del Señor ${ }^{29}$

Esta breve exposición de la cristología de oriente permile ver notables convertencias con la TL. No se trata sólo de la importancia del Jesús histórico resaltada tanto por la cristologia antioquena como por la $T L$, sino del enfoque global: la orientación global a la vida, la importancia de la encarnación y de la kénosis, el triunfo de la vida sobre la muerte en la resurrección, la vida del cristiano como algo más que la imitación de Cristo, la importancia del reino, la necesidad de ir pasando de la muerte a la vida, la función de María en toda la economía de la encarnación, la solidaridad como estilo de vida cristiana, la necesidad de transfigurar el cosmos, elc. ${ }^{30}$

Evidentemente la TL tiene una acentuación histórica y, en concreto, de la tarea a favor de la justicia que tal vez no se halle tan clara en la TO, aunque no se puede olvidar la constante referencia a este tema de la justicia en los Padres del siglo IV ${ }^{31}$

Sin embargo, se interpretaria mal la cristologia de la TL si se creyese que para ella la encarnación se reduce a la dimensión puramente ética y Jesús a un mero profela social del Antiguo Testamento. La salvación es liberación plena de la muerte e incluye la vida en todas sus dimensiones, como afirma claramente J. Sobrino. ${ }^{32}$

La justicia no es algo meramente ético para la TL, sino la forma teológica cómo Dios ha actuado con los pobres a lo largo de toda la historia de salvación, desde el éxodo de Jesús, como repite constantemente Gustavo Gutièrrez. ${ }^{33}$

La TL historiza el tema de los dioses de la muerte que condenan a Jesús (la teocracia judia y el imperio romano) y sus enfrentamientos continuos con el Jesús hisı́rico, ${ }^{34}$ pero no reduce la pasión y muerte de Jesús a simples coyunturas históricas accidentales, sino que ve en ellas la realización histórica de una salvación trascendente $;$ universal.

Por olra parte, el cema clásico en la TL de la solidaridad de Jesús con los pobres puede hallar en la formulación de la TO sobre la consubstancialidad (homousios) de Jesús con la humanidad una profunda fundamentación teológica, y el seguimiento del Jesús histórico, tan acentuado por la TL, se puede enriquecer con la visión de la TO sobre la kénosis y el descenso de Jesús a los infiernos. La figura de Cristo sacando de los infiernos a Adán y Eva, puede ser la expresión iconográfica de la praxis que propicia la TL en un continente no 
sólo condenado a muerte prematura, sino que en tantos aspectos está en los infiernos.

Finalmente, la figura de la Theotokos, siempre llevando en sus brazos al Niño, tan venerada en el orientc, tiene profundas resonancias en América Latina, visitada por María con el Niño en brazos y los pies descalzos, cuya teología no conoce los minimalismos mariológicos de cicrtas corrientes occidentales, sino que ve en ella el "rostro maternal y misericordioso de la cercania del Padre y de Cristo." 35

\section{Pneumatología}

Para la TO la misión del Espíritu forma parte de la economia trinitatia ${ }^{36} \mathrm{Si}$ el Logos es estructura, razón, causa, el Espiritu es vida, dinamismo, devenir, interioridad, cumplimiento. El Espiritu prepara la obra de Cristo y la lleva a plenitud: es la línea que destaca la corriente siro-antioquena, siguiendo a Lucas. Pero también es verdad que el Espiritu es don de Cristo, conforme a la tradición joannca que hace suya la escucla alejandrina. Toda la tradición del oriente concede gran importancia al Espiritu y acusa a la teología latina clásica de haber olvidado esta dimensión penumatológica de la le. Para la TO, la venida del Espiritu en pentecostés no es una simple continuación de la encarnación, sino el fin último de la economía, el fuego que Cristo quiso traer a la tierra (Lc. 12,49), la venida para la cual era preciso que el Hijo volviera al Padre (Jn. 16,7) y fuera glorificado (Jn. 7,38). Atanasio afirma que el Verbo se ha encarnado para que el hombre reciba el Espiritu y Evdokimov llega a decir que Cristo es el precursor del Espíritu. Pentecostés señala el comienzo de la Iglesia, e! inicio del reino y de la parusia. Y algunos padres en el Padre Nuestro sustituyen el "venga tu reino" por "venga tu Espiritu." La TO destaca el aspecto misterioso y de ocultamiento del Espiritu, su anonimato silencioso, aún después de pentecostés. Sus imágenes son fluidas: soplo, viento, llama, perfume, paloma, zarza ardiente. Existe como una kénosis también el Espiritu.

El Espíritu se manifiesta a través de sus dones increados, las energias divinas que todo lo transfiguran. La Iglesia pide estos dones en la epíclesis litúrgica.

El icono de pentecostés represcnta a un viejo encarcelado: es el cosmos que espera la salvación de Cristo y el don del Espíritu para ser liberado y transfigurado.

Un famoso texto del actual patriarca Ignacio Vl de Antioquia, pronunciado en 1968 en el consejo ecuménico de iglesias en Upsala, expresa bien la mentalidad oriental sobre el Espíritu.

Sin Espiritu Santo, Dios está lejos,

Jesucristo queda en el pasado,

el evangelio es como letra muerta,

la misión, una propaganda,

la autoridad, una dominación, 
el culto, una evocación.

el actuar cristiano, una moral de esclavos.

Pero en el Espiritu, en una sinergia indisociable,

el cosmos es exaltado y gime hasta dar a luz el reino,

Cristo resucitado está presente,

el evangelio es una potencia de vida.

la Iglesia significa la comunión trinitaria.

la autoridad, un servicio liberador.

la misión, un nuevo pentecostés,

la liturgia, un memorial y una anticipación,

el accuar humano, es divinizado. ${ }^{37}$

La TL tambièn reconoce que la pneumatologia ha sido olvidada en la tradición occidental, consecuencia en gran partc de la herencia agustiniana. Este otvido ha tenido graves consecuencias tanto en la eclesiologia, como en las relaciones del cristianismo con el mundo. Comblin actualiza el tema clásico de la TO sobre las dos inisiones y su complementariedad. ${ }^{38}$ De esıas dos misiones se deducen las dos fuentes de la teología. No se trala de volver a la vieja discusion antiprotestanıe, sino de señalar el unilateralismo de una inspiración exclusivamente biblica de la reología. Es en la historia de la Iglesia donde se nos revela el sentido pleno de la praxis de Jesús. Es el Espíritu el que actualiza en la historia el evangelio, le da contenido histórico y alienta a los cristianos a responder novedosamente a los nuevos desafios de la historia. El Espiritu hace que la salvación alcance a la historia y la fermenta de forma imprevisible, ofrece grandes horizontes para la evangelización y la liberación y posibilita un seguimiento de Jesús en nuestra lyistoria. A través de acontecimientos aparentemente mundanos y profanos el Espirilu hace avanzar la historia hacia el reino. Los signos de los tiempos no son más que momentos incandescentes de esta esperanza que se va anticipando en la hisloria.

Seguramente la TL puedc profundizar más estas perspectivas penumatológicas, sacando nuevas consecuencias para la cristologia, la eclesiologia y la espiritualidad. Esto le ayudaria a superar cierto aire moralista y voluntarista que a veces puede empeñar las dimensiones más teológicas de la TL.. Mientras en la teologia contemporánea del primer mundo el redescubrimiento del Espiritu puede derivar hacia un entusiasmo carismático un tanto ambiguo y a veces alienante, la TL está en las mejores condiciones para mostrar la unidad entre la misión del Espiritu y la del Hijo, entre Espiritu y seguimiento de Jesús, ya que es precisamente el Espiritu quien unge a Jesús y lo envia a liberar a los oprimidos y a anunciar el evangelio a los pobres (Lc. 4,16 ).

Por olra parte pocleınos preguntarnos si cierta dificultad de la teologia del primer mundo para comprender y aceptar la TL, no nacerá de su misma concepción fixista y poco pneumárica de la revelación, de la Iglesia y de la teología. 


\section{Trinidad}

Para la tradición oriental, la teologia es ante todo contemplación del misterio trinitario y la trinidad marca la TO: la antropología (el hombre cs imagen de la trinidad), la eclesiologia (la Iglesia es la trinidad terrena), la vida espiritual (divinización trinitaria) y la misma vida social (que se configura a imagen de la trinidad. Como dice el teólogo Florensky "entre la Trinidad y la vida no hay término medio."

La TO sobre la trinidad se desarrolló en torno a los primeros concilios ecuménicos y sus líneas de fondo son diferentes de las occidentales latinas. Sin querer penetrar en el tema, podemos señalar algunas de las diferencias clásicas e irreconciliables entre las dos tradiciones teológicas. I_os latinos parten de la naturaleza divina para llegar a la persona, los orientales parten de la persona para llegar a la naturaleza. Los lalinos consideran la persona como un modo de la naturaleza y los orientales consideran la naturaleza como contenido de la persona. Para los latinos la unidad de la trinidad proviene de la naturaleza, para los orientales la unidad trinitaria tiene su origen en el Padre, principio único, al cual hace mención el Nuevo Testamento cuando habla de Dios. ${ }^{39}$ Para los latinos todo es común a las personas menos las relaciones de oposición que constituyen el origen de las personas, para los orientales las relaciones de oposición no son el único fundamento de las personas. Los latinos ven en los orientales peligro de subordinacionismo, los orientales creen que los latinos despersonalizan la trinidad en aras de un esencialismo abstracto: la divinidad, el buen Dios. Para los latinos la gloria consiste en la visión de la esencia divina, para los orientales en la participación de la vida trinitaria a través de Cris10 .

Estas diferencias llegaron a un punto polémico en la cuestión del Filioque. No vamos a entrar en este espinoso debale. Digamos tan sólo que orientales ecuménicos, como P. Evdokimov, creen que el Filioque latino debería completarse con el Spirituque (Lc. 1,$35 ; 4,18$ ). Es decir, cada persona debe ser contemplada conjuntamente con sus relaciones con las otras dos: el Espíritu procede del Padre, pero el Hijo está presente en esta procesión, el Hijo es engendrado por el Padre, pero el Espíritu está presenle en la filiación.40

La TO ve en el icono de la trinidad de Roublev la expresión de su fe. Los tres ángeles de la misteriosa teofania a Abraham expresa la armonia y mutua comunión ternaria, es una pericoresis amorosa y alegre que se vuelve misericordiosamente hacia el mundo creado y libera a la creatura caída, clevándola hacia Dios. De esta misteriosa koinonia trinitaria brota un espiritu de comunión y solidaridad que abraza la humanidad y el cosmos. ¿Es casual que los doctores de la trinidad hayan sido los defensores de la dignidad de la persona humana, incluso en tiempo de la esclavilud? ¿Es casual que el oriente trinitario tenga una visión más comunitaria de la tierra que el occidente de tendencia más monoteísta?

La TL ha desarrollado todavía poco el tema trinitario.4l La razón de este silencio no es, como a veces se ha insinuado, por que la TL es más una ética so- 
cial que una teologia, sino por la necesidad primaria de la TL de elaborar antes una crislologia e incluso una pneumalología. Solo desde la economia sc puede llegar a la teologia.

Pero esta tarea trinitaria es una meta propuesta, que tarde o temprano la TL. tendrá que abordar. Tanto más que la teologia moderna (J.M. Lochmann, E. Petcrson, J. Moltmann) considera cada ve $\angle$ más que existe una relación estrecha entre la imagen trinitaria y la configuración, no sólo de la lglesia, sino lambièn de la historia y de la sociedacl.

Por otra parte, la diferencia entre la doctrina trinitaria de la TO y de la teologia latima es un ejemplo claro de cómo se puede mantener la unidad de la fe más allá de las difcrentes tcolngias. Lo que hay que evitar es que la rabies theologica envenenc el diálog̣o en polémica dogmática. Escribe P. Evdokimov:

El debate dogmático de los teólogos sobrc el Espiritu Santo manifiesta una

Tlagrante falta de Espíritu y constituye la mayor paradoja de la historia. ${ }^{42}$

\section{Eclesiología}

Para la TO la Iglesia es mucho más que una institución, "es una vida nueva con Cristo y en Cristo, dirigida por el Eispiritu Santo," 43 " "es la vida divina que se manifiesta en la vida de las creaturas, es la divinización de la creatura por la fuerza de la encarnación y de pentecostés." 44 Para conocer la Iglesia hay que experimentarla, hay que vivir esta vida nueva trinitaria comunicada al mundo en la lglesia de Cristo.

La TO recalca los dos principios estructuradores de la eclesiología, el cristológico y el pneumático. Por el principio cristológico la Iglesia es el cuerpo de Cristo y su expresión actualizada es la celebración eucaristica. Esta eclesiología eucaristica, ampliamente desarrollada por Afanasiefr, tiene su base primera en la Iglesia local. La eucaristía no revela la dimensión sacramental de la Iglesia, su poder transfigurador del universo y de la historia, el ser matriz histórica del reino. Por otra parte, esta dimensión eucarística de la lglesia se enlaza con la jerarquía, los sacramentos, la escritura y toda la Iglesia universal, constituyendo como la nervadura ontológica de la institución eclesial.

Pero este principio cristológico se completa con el principio pneumatológico. La Iglesia se fundamenta en la eucaristía y pentecostés. La dimensión cristológica de la Iglesia queda penetrada por el Espiritu, que es el que vivifica toda la estructura eclesial. Es la epiclesis o invocación al Espiritu la que edifica la lglesia y transforma los dones eucarísticos. La lglesia, pues, no es sólo anámnesis de la fundación histórica de Cristo, sino tensión hacia el Cristo que viene, hacia el reino por el Espíritu. La misión de la Iglesia es ir transformando el mundo en el reino, Iransfigurar la historia y el cosmos por la energía divina.

Sin entrar en el tema polemico del primado petrino, una de las raíces de las pocas diferencias dogmáticas entre catolicismo y ortodoxia, podemos afirmar que la eclesiologia oriental es una eclesiologia de comunión, donde jerarquia, magisterio, sacramentos, carismas y disciplina eclesiástica se ordenan a la koinonia. La llamada "economía de la misericordia" por la cual los 
obispos adaptan pastoralmente a los fieles las normas eclesiásticas, la doctrina de la "recepción" por la que toda la Iglesia asimila activannente nuevas proposiciones doctrinales, la parlicipación del pueblo en la elección de sus pastores, la concepción del ministerio sacerdotal como el que actia no sólo in persona Christi, sino también in persona ecclesiae, la sintonia con la tradición ecuménica y la comunión entre las diferentes iglesias locales, son todo ello expresiónes de esta eclesiologia de comunión, de la sinlonia eclesial, de la llamada sobormost (Khomiakof), la cual sintetiza la autoridad ! la liberiad, supcrando tanto ef individualismo como el autoritarismo.

La eclesiologia oriental es eminentcmentc litúrgica: celcbra la salvación del hombre recordando la vida de Cristo (anámmesis), invocando el Espiritu (epiclesis) y anticipando el futuro del reino (prognosis cscalológica). Por la liturgia se santifica el hombre y el mismo cosmos - que gime en dolores de parto-, se transfigura, comenzando por los inismos elementos sacramentales: pan, vino, agua, accitc. El hombre, al acabar la celebración, debe prosegnir extra muros la liturgia eclesial. Existe una profunda conexión entrc el sacramento del altar y el sacramento del hermano. Los padres de la Iglesia desarrollaron en sus homilias litúrgicas una verdadera doctrina social, o mejor dicho, la dimensión sacramental de la solidaridad humana: denunciaron la injusticia social de su liempo, elaboraron una tcologia sobre el destino universal de los bienes de la tierra y sobre la subordinación de la propiedad privada al bien común, y establecieron mecanismos para la comunicación de bienes en torno a las of rendas eucaristicas. Su defensa de los pobres, su lucha contra la esclavitud considerada normal en aquel tiempo, sus duras invectivas contra los poderosos, les valieron persecuciones y exilios. Los padres son un modelo de integración entre liturgia y vida, entre fe y justicia.

La liturgia y piedad oriental tiene un carácter marcadamente popular, ofreciendo un modelo ejemplar de unidad entre liturgia y religiosidad popular. Tal vez uno de los factores más decisivos para esta integración es el carácter simbólico y festivo de su liturgia, lo cual la diferencia del acento marcadamente intelectual y ético de la liturgia de la Reforma, centrada casi exclusivamente en la palabra. Una de las manifiestaciones concretas de esta dimensión simbólica de la TO es el icono. El icono no es una simple representación realista de un santo, ni un simple recuerdo pictórico del Señor o Maria, sino un sacramento que hace presente y comunica la gracia de la salvación a Iravés del símbolo representado. El icono es bendecido y nos invita a comulgar con el misterio. El icono de Cristo no representa simplemente la naturaleza humana de Cristo, sino que intenta revelarnos el mismo misterio de su persona divina, en una como teofanía de la transfiguración. P. Evdokimov define el icono de Cristo como "una representación simbólico-hipostática que invita a trascender cl símbolo, a comulgar con la hipóstasis, para participar del Indescriptible.' 45 Toda esta visión presupone una teología simbólica, cósmica y estética, canonizada por el séptimo concilio ecuménico contra los iconoclastas. Atanasio, Basilio, Máximo Confesor, Teodoro Estudita y Juan Damasceno fueron los grandes defensores del icono contra los iconoclastas de origen arriano y docetista. La dimensión de la belleza es un componente de la TO. La expresión de Dostoievsky "la 
belleza salvará el mundo," que Soljenitsyn hará suya, es un claro exponente de la teologia de la belleza típica de la Iglesia del oriente.

La eclesiologia de la TL parte tambièn del doble principio cristológico y pneumatológico en la estruclura cclesial y acentía la acción del Espiritu en el nacimicnto y desarrollo eclesial. L. Bofr ha acuñado el término de "eclesiogénesis" para designar este dinamismo eclesial, intimanente ligado al Espiritu. 46

La TL reaiza también la orientación de la Igiesia al reino y la necesidad de que la Iglesia vaya convirtiéndose comlinuamente a ćl. ${ }^{47}$ Sin duda, la TL acenlúa más que la TO la acción histórica y reformadora de la Iglesia en el mundo, pero la tensión escatológica es común a ambas eclesiologías, a diferencia de las eclesiologias de cristiandad que fienden a idenlificar la Iglesia con el reino. Tanto la TO como la TL recalcan la dimensión no meramente juridica o institucional de la Iglesia, sino su sentido vital. La lglesia es sacramento de la vida y está al servicio de la vida en todas sus dimensiones. Por orra parte, es común a ambas cclesiologias la imporlancia de la lglesia local. como cédula germinal y punto de arranque de toda eclesiología. Las comunidades eclesiales de base de la TL son la versión latinoamericana de la eclesiologia local de la TO, aunque la carencia de ministros haga que esta comunidad de base a veces no pueda llegar a su plenitud eucarística. Las discusiones sobre el ministro de la eucarislia en las comunidades de base de América Latina no nacen de una visión antisacramental, ni de un deseo de marginarse de la jerarquia, sino al revés, de una preocupación por la participación eucarística para comunidades privadas por largo tiempo de sacerdote. 48

También es común a ambas teologias el interés por unir el sacramento del altar y el sacramento del hermano, que la TL formula como el sacramento del pobre, conforme a Mateo 25. La doctrina patrística sobre la justicia halla profundo eco en la TL que ha estudiado y publicado nuevamente textos patrísticos ${ }^{49}$ y ha buscado en los obispos evangelizadores de los siglos XVIXVII formas latinoamericanas de esta sintesis patristica entre re y justicia. ${ }^{50}$. Las eucaristías de Mons. Romero, ¿no serian un ejemplo actual de esta sintesis entre eucaristia y vida? La doctrina sobre la "hipoteca social" que grava toda propiedad privada, de Juan Pablo II, y recogida por Pueblas' es un eco latinoamericano de la preocupación patrística por la justicia.

Es verdad que al TL no ha desarrollado aún ampliamente la sacramentalogia,pero en sus ensayos apunta también hacia la dimensión escatológica y utópica de los sacramentos. Estos, al anunciar el reino, llaman a la Iglesia a la realización de una historia que se aproxima lo más posible a los valores de reino que Jesús anunció. Y al mismo tiempo previene contra el peligro de una liturgia separada de la vida, en la cual el rito sustituya al compromiso.52

La dimensión vitalista y terapéutica de los sacramentos de la TO, así como su sentido cósmico, pueden servir a la TL de inspiración para ulterior desarrollo en clave de liberación. En general, la dimensión de comunión, típicamente oriental y que el Vaticano II felizmente ha recuperado, por lo menos parcialmente en la $L$ umen gentium, ${ }^{53}$ halla una gran resonancia en la $T L$, la cual insiste en que la lglesia de los pobres es el sacramento histórico de una 
Iglesia de comunión: a ellos debe ir dirigido prioritariamente el mensaje liberador del evangelio, ellos deben ser sujetos de la Iglesia y de la sociedad, y constituyen un polencial evangelizador de primera magnitud para la Iglesia. La TL ha rellexionado más ampliamente sobre el pueblo de Dios, pueblo pobre, Igle 1 y reino. ${ }^{54}$ En general, la eclesiologia de la IL tiene una mayor impronta histórica que la TO.

Es común a ambas eclesiologías la preocupación por comprender, purificar y asimilar la religiosidad popular. $\$ 5$ La TO posce la ventaja de que no permitió que la religiosidad popular creciese al margen de la liturgia, mientras que la TL se halla con una religiosidad popular nacida al margen de la religiosidad oficial y litúrgica, quizás por el hecho de que la primera evangelización en América Latina estuvo en manos de una lglesia latina que, por lo menos desde el siglo Xl, se habia ido distanciando cada vez más de pueblo en su liturgia, dogmas y disciplina. La TO puede of recer a la TI notables modelos de integración de la religiosidad popular, y, en concreto, la teología del icuno debería ser estudiada más por la TL. La devoción del pueblo pobre y sencillo de América Latina a sus "santitos," tan mal interpretada teológica y pastoralmente por agentes pastorales imbuidos por una mentalidad secular, ajena a la situación real de la mayoria de latinoamericana, puede iluminarse en muchos aspectos por la visión más simbólica y sacramental de la TO sobre los iconos. Y, en general, resulta insuficiente para la situación de América Latina recuperar la teología de la palabra, siguiendo los esfuerzos ecuménicos del Vaticano II. Es necesario elaborar una teología del símbolo, ligada más a la vista que al oído, y que empalma con la mentalidad popular de América Latina. La expresión oriental "la belleza salvará el mundo" puede tener un sentido liberador. No es la belleza pagana y fría del arte - que en el primer mundo viene a sustituir muchas veces la religión- sino la belleza de Dios, de Cristo, de los santos y de María, a la cual el pueblo sencillo da culto en sus santuarios y en sus casas, como espacios simbólicos y sacramentales de la misericordia de Dios, quien en sus imágenes se acerca amorosamente a los pobres. La piedad del pueblo oriental que coloca velitas a sus iconos, no está muy lejos de la devoción del pueblo latinoamericano para con sus "santos." Los espiritus racionalistas y "bienpensantes" del primer mundo, seguramente consideran superstición todas estas prácticas populares, pero en realidad en ellos se esconde, a menudo, algo muy profundo y evangélico: la fe de los pobres y su clamor ante Dios.

\section{Espiritualidad}

Si es dificil hallar líneas comunes a los diferentes temas de la TO (antropologia, cristologia, pneumatología, trinidad, eclesiología), mucho más lo es el hablar de la espiritualidad, en cuanto que ésta posee un marcado carácter personal y acusa profundamente las variaciones históricas y culturales. ¿Qué puede haber de común entre la espiritualidad primitiva de los padres apostólicos centrada en el amor y el martirio, la espiritualidad intelectualista de los alejandrinos quienes todo lo orientan a la contemplacion y a la apatia, la escuela del existencialismo experimental de los bizantinos como Simeón el 
Nuevo Teblogo, la escuela cenobitica del monacato basiliano, la espiritualidad hesicasta de Gregorio Sinaita, o la mistica rusa del staresz y del peregrino de la "oración de Jesús"'? 56

$Y$, sin embargo, hay constantes comunes a todas estas corrientes. En primer lugar, lo que llama la atención es la estricta vinculación entre teología y e5piritualidad. Oriente no conoció el divorcio entre teologia y espiritualidad que en occidente se consumó hacia el siglo XIV ${ }^{57}$ La teologia es expresión de la vida espiritual y se orienta hacia ella. Para el oriente los grandes teólogos son los misticos (Juan el evangelista, Gregorio de Nisa, Simeón el Nuevo Teólogo), y consideran sospechosa una teología que no vaya acompañada de una vida santa. La teologia, al margen de la espiritualidad, degenera en orgullo, herejía Por esto los monjes del desierto se apartaban de las especulaciones teológicas.

La espiritualidad para el oriente es una vida, y más que hablar de imitación de Cristo prefieren hablar de la vida en Cristo (N. Cabásilas). El carácter "biológico" del oriente aparece de nuevo aqui. Esta vida tiene diversas edades o etapas. ${ }^{58} \mathrm{Su}$ fundamento es cristológico, pneumatológico y eclesial. La economia del Hijo y del Espíritu, presentes en la Iglesia, posibilitan esta nueva vida en Cristo.

Pero la TO insiste en la necesidad de una respucsla personal a la gracia, el llamado "sinergismo." Este no debe entenderse como moralismo pelagiano, sino como misteriosa acción de la gracia que fermenta la masa de la libertad humana. La primera etapa de la vida espiritual es la metanoia, la conversión, un cambio de orientación total, un salir de la philautio o egoísmo personal, un nuevo nacimiento, dejando el estado de burguesía espiritual del que se cree farisaicamente justo, y sentirse pecador, experimentando "el temblor del alma ante las puertas del paraíso" (Isaac Sirio). Este paso va acompañado de lágrimas, el penthos o compunción. ${ }^{59}$

Esta conversión inicial abre el paso al combate espiritual que es la lucha contra los logismoi o malos pensamientos que vienen del maligno y que aprisionan la caridad. Pcro este combate espiritual es en última instancia contra el maligno, contra las polestades demoniacas (E「. 6,12). Esta lucha prolonga en la Iglesia la lucha de Cristo contra el demonio en las tentaciones y en la cruz. En este combate, los monjes, con su maximalismo escatológico, constituyen una etapa fundamental, un momento dialéctico inevitable de la espiritualidad cristiana, que todo cristiano debe interiorizar. La cumbre de la vida cristiana es la contemplación unida a la caridad. La caridad es la condición de la oración y su fruto. Asi se llega a una vida Iransfigurada, a una vida en el Espirilu, a la salud y liberación plena, cuya cima es la santidad.

La cumbre de la santidad humana es la Theorokos, llena del Espiritu, la nueva Eva. Pero hay tres tipos dc santidad especialmente estimados en el oriente: el mártir, perfecto seguidor de Cristo y prototipo de santidad; el monje, prolongación del martirio en tiempo de no persecución; y el "loco por Cristo" quien vive la locura de la cruz ( 1 Cor. 1,17 ), y se hace necio por Crislo. $O$. Clément ve como dos líneas constantes en la Iglesia oriental, la de la luz y la de la sangre, la luz del Tabor de los místicos y la sangre de los mártires.60 
La TL parte del hecho de que su reflexión teológica nace de una experiencia espiritual ligada a la praxis de liberación. Sus teólogos repiten que su punto de partida es una experiencia de Dios en el pobre, del paso pascual del Señor en el proceso liberador. El pobre y su liberación son un auténtico lugar teológico. G. Gutiérrez afirma claramente que en la historia de la teología se constata que loda leologia viva nace de una experiencia espiritual.61 Aqui radica, seguramente, la vitalidad de la $\mathrm{TL}$ frente a otras teologias modernas.

Este planteamiento zanja de raiz la dicotomía entre teologia y cspiritualidad que ha paclecido el occiclente durante siglos. Si la TL tardó en explicitar la espiritualidad fue más por molivos de coyuntura histórica que intrinsecos.

También la TL. habla de la importancia de la conversión como punto de arranque de la vida cristiana: conversión de los idolos de muerte al Dios de la vida, conversión del pecado personal y estructural al reino. Esta conversión pasa por la mediación del pobre: es conversión al pobre, sacramento histórico de Cristo hoy en América I atina. Esta conversión al pobre presupone escuchar su clamor ${ }^{62}$ y no se agota en las lágrimas del arrepentimiento personal, sino que presupone una continua solidaridad con los que lloran. A esta conversión sigue una lucha contra los "demonios" de la injusticia y del pecado, que cristaliza en las estructuras injustas, que afectan profundamente a cada persona. Su objetivo es la liberación radical del pecado y de sus consecuencias personales y sociales, auténtico exorcismo colectivo que supera las fuerzas humanas y llevaria al desánimo si no contase con la fuerza de la resurrección. Es en esta misma lucha, en la noche oscura de la injusticia estructural (Hernández Pico), donde se encuentra a Dios contemplativus in liberatione (L. Boff), contemplativo en la acción política (G. Gutiérrez), siguiendo el modelo de la oración de Jesús (J. Sobrino).

La espiritualidad de la liberación, como la de la TO, insiste más que en la imitación de Cristo en el scguimiento de Jesús, en vivir la vida de Cristo en nuestra historia. Hay tambièn una dimensión fuertemente "biológica" y una insistencia en la necesidad de una respuesta personal y activa al llamado de Dios. Indudablemente, la TO posee un carácter más monástico y contemplativo que la TL, pero ésta no rehuye tratar temas clásicos como el silencio, la soledad, la oración, la infancia espiritual y la contemplación. La fuente y raiz de la espiritualidad de la liberación cs el Espiritu de Jesús, el que le ungió para evangelizar a los pobres (Lc. 4,18), y que nos interpela hoy a vivir siguiendo a Jesús cn nuestra historia concrela en América Latina.

Notable es también la coincidencia de ambas teologias sobre el martirio como prototipo de santidad. Mientras el tema del martirio parecia ausente de la teologia moderna europea, la TL lo ha actualizado con fuerza como consecuencia de las persecuciones de la Iglesia en América Latina en estos últimos años. Es un martirio diferente del clásico, ya que los que hoy asesinan en América Latina dicen hacerlo en nombre de la civilizacion cristiana occidental, mientras que los asesinos de los primeros siglos se confesaban enemigos del Dios de los cristianos. La vida religiosa también recobra en América Latina nuevo vigor, precisamente en la medida en que se compromete con la libera- 
ción de los pobres y se vuelve a situar "ell el desierto, el margen y la frontera" 63 de la sociedad y de la Iglesia establecida. Finalmente, la locura de la cruz vuelve a ser principio inspirador de la teologia liente al conlormismo y mundanización del racionalismo ambiental implicado en la lógica del dinero y del poder.

Cuando la TL afirma que la reologia es posterior a la praxis liberadora, o que su interés último no es la teologia, sino la liberación, no está haciendo más g̣ue priorizar la dimensión de la vida sobre la de la razón. L.a Tl., de hechn. ayuda a muchos cristianos y comunidades de basc a vivir mas lielmente su compromiso cristiano por la liberacion, y este compromiso relroalimenta a la reflexión leológica. Un nuevo kairos esta surgiendo en América Latina, la cual en medio de dolores de parıo alumbra al nuevo por obra del Espiritu de Jesús. $Y$ en este doloroso alumbramiemo. Ll pueblo pobre y creyente juega un papel importante:

El Pueblo te hizo santo,

la hora clel pueblo te comsagró en el kairós.

Los pobres te enseñaron a leer el evangelio.

escribe el obispo Casaldáliga refiriéndose al martirio de Mons. Romero.

\section{Escatología}

La TO tiene una clara tendencia hacia la consumación escatológica, al reino. Esta escalologia ya ha comenzado con la resurrección y pentecostés, y la Iglesia la anicipa litúrgicamente: la transfiguración ya esıa en obra, la fiesıa ya ha comenzado.

Sin embargo, los misınos teólogos orientales afirman que si la tentación occidental es el construir aqui la ciudad secular sin escatologia, la tentación oriental consiste en buscar una escalología sin historia. Para algunos orientales, como luego veremos, el comunismo ruso scría una reacción atea a una escatologia ortodoxa excesivamente espiritualista. reintroduciendo el problema de la historia.

Por todo ello la TO, sobre todo la comtemporánea, intenta sintetizar en su afirmación escalológica la aceplación positiva de la realidad, la purificación exorcística y la trascendencia transfiguradora. En el terreno cultural, la TO intenta purificar la realidad del nuundo en todas sus dimensiones, hasta hacerla iransparcule al reino. El verdadero dualismo no estriba en la diferencia profano-sagrado, sino entre hombre viejo y hombre nuevo. La cullura debe ser un icono del reino, preparando los caminos del Señor en su uiltima venida.

La reflexion oricnal modema reconoce que clebe profundizar más el rema económico-social, voviendo a los elementos más comunitarios de su tradición: el sentido comunitario de la tierra, cuya propieclad es de Dios; la doctrina patristica (Basilio, Crisóstomo...) sobre la injusticia de unos pocos que poseen en exclusividad los bienes de la tierra destinados a todos; la teologia trinitaria en la cual las personas no existen más que en relación y comunión; la teologia de la persona humana como ser en alteridad y comunión; la consubstanciali- 
dad de todos los hombres; la lglesia como cuerpo comunitario de Cristo vivificado por el Espíritu; en fin, la doctrina eucaristica del pan compartido.

Los téologos y pensadores rusos modernos (Federov, Berdiaev, Boulgakov, Evdokimov, Soljenitsyn...) han reflexionado sobrc el socialismo y el comunismo rusos. Para eilos el socialismo moderno ha nacido de la parte del evangelio que la lglesia no habia asumido. Fl socialisino no se encontró con un cristianismo vigoroso, sino con un pictisıno y un individualismo, ya que el crislianismo occidental habia scparado y opuesıo el sacramento del altar y el sacramento del hermano. Por esio luvo que ampararse el el marxismo. Aliora bien, el marxismo incluye elementos separables: la racionalidad cientifica y una [ilosofía de contrabando, que lo convierten en una auténtica religión. La dimensión critica del sistema capitalista, del lucro dc la avaricia, es aceptable. En cambio la dimensión alea y totalitaria de su filosofia es rechazable. Esta parte filosólica, sobre todo en el comunismo ruso, es la transposición atea del ansia mesiánica del pueblo ruso, de su nilenarismo apocaliptico y nacionalista. El comunismo ruso es lógicamente un mesianismo rcligioso y, a pesar de su materialismo ateo, posee el misticismo, dognatismo y el totalitarismo absoluto del milenarismo religioso. El desafío a que la TO se siente llamada es a recuperar todas las dimensiones comunitarias e históricas del reino, despojándolas de sus adherencias ateas, las cualcs han sustituido el reino por una utopia colectivista y a la Iglesia por el partido.64

Para Evdokimov la escatología y el apocalipsis tienen incidencia histórica, cada época posee su propia escatologia y juicio inırahisıórico, y en ella se debe descubrir la voluntad de Dios. El fín del mundo está oculto en la voluntad trascendente de Dios. Es en la historia donde hay que saber discernir los signos de los tiempos en estos apocalipsis intrahistóricos, de los que la revolución rusa es uno de ellos. 65 En fin, en frase conocida de N. Berdiaev, "el problema del pan del prójimo es un problema material para él, pero para mi es un problema espiricual."

La TL más que elaborar una escatologia sistemática, posee una escatologia implicita. La realidad de injusticia, hambre y miseria de América Latina ha llevado a interiorizar sobre sus causas, descubriendo que éstas no son fortuitas, sino dependientes del sistema capitalista dominante en el que viven y mueren estos paises. Esto le ha llevado a una denuncia prolélica de las estructuras de pecado y a una critica de ciertos tipos de cristianismo individualista y alienante que parecen bendecir o silenciar esta situación. Aunque la TL no propugna ningún modelo socio-económico concreto, evidentemente no ha podido menos de dialogar con las ideologias existentes, con el socialismo $y$ el marxismo, intentando discernir lo que en ellos hay de racionalidad cientifica y lo que es fruto de una utopia filosófica inacepiable. La TL sc halla ante un desafio semejante al de la TO: evitar la resignación fatalista ante una situación de grave injusticia y no caer en el milenarismo, superar una visión puramente histórica del reino y no sacralizar cualquier movimiento intrahistórico identificándolo con el reino consumado. Para ello se requiere una actitud de discernimiento continuo, desenmascarar lo demoniaco que desfigura el plan de Dios y buscar en la historia presente las señales del reino de Dios que se debe ir edifi- 
cando. La TL cree que su misión es ir acompañando al pueblo en su búsqueda liberadora, ayudándole a ser crítica y anunciándole la plenitud del reino. La liberación sería la versión latinoamericana de la transfiguración del mundo a la cual propende la TO. Al texto de Berdiaev sobre el pan del prójimo como problema espiritual para ini, corresponden estos versos de Casaldáliga:

Donde hay pan, alli está Dios.

Somos familia en la lracción del pan.

Sólo al partir el pan

podrán reconocernos.

Seamos pan, hermanos. ${ }^{66}$

\section{Epílogo}

Tal vez este largo recorrido por los diversos temas teológicos nos permite superar el asombro inicial del Videlur quod non... y reconoce que sed contra... entre la TO y la TL hay interesantes punıos de aproximación y de complementación.

Sin intentar una recopilación de todo lo dicho hasta ahora, si podemos sacar algunas consecuencias de este cotejo. En primer lugar, la TL, a pesar de su innegable originalidad y de su reciente aparición, liene profundas raíces, no sólo en la escritura, sino en la tradición teológica de la lglesia (parristica y oriental). El hecho de que en tantos aspectos resulte novedosa para muchos ¿no se deberá, tal vez, a que se la juzga sólo desde la teología latina occidental clásica o incluso moderna?

En segundo lugar, el tema de la liberación viene a ser como el equivalente teológico latinoamericano de la transliguración oriental. ${ }^{67}$ En ambos casos se parte de la realidad desfigurada y demoniaca que hay que transfigurar, liberándola de lodo lo que sea pecado y muerte, para que participe ya ahora de la plenitud de la vida de Dios que en Cristo se nos ha comunicado y que el Espiritu fecunda.

En tercer lugar, la existencia de un pluralismo teológico en la tradición de la lglesia permite comprender y aceptar mejor la legitimidad de las diversas teologias en la Iglesia actual. Si durante siglos han podido coexistir en la catholica una teologia latina y olra oriental ino podrán coexistir hoy una leologia europea y otra latinoamericana o del tercer mundo?

En cuarto lugar, también parece claro y urgente acabar con el eurocentrismo teológico de los últimos siglos, lo cual no supone romper con la catolicidad ni menos con Roma, sino distinguir la auténtica comunión con Roma de una uniformidad teológica.

En quinto lugar, frente al actual invierno teológico europeo, confesado por muchos, hay que reconocer que las dos alas más ricas de la teologia contemporánea se mueven en el segundo y en el tercer mundo. Esta constatación no supone ni desprecio ni falso entusiasmo, ya que el diálogo de las diversas 
teologias será siempre fruclifero y necesario, para expresar con mayor plenilud la le de la comunidad eclesial y el cvangelio.

En sexto lugar, en concreto, el diálogo entre la TO y la TL puede ser mutuamente enriquecedor. la TL, de hecho, ha historizado muchas de las afirmaciones más genéricas de la TO, y esto no simplemente por deducción lógica de unas premisas, sino partiendo de una realidad de injuslicia y muerte. I.a TL puede hallar en la TO rundamentación y confirmación tcológica de muclıas de sus intuiciones y afirmaciones liberadoras: las nociones de koinonia, vida, pecado como muerte, reino, Espiritu, escatologia, kénosis, descenso a lus inficrnos, cransfiguración, iconografía... La TO en diálogo con la TL puede evilar su constance riesgo de tender a una cscalología suprahistórica.

En fin, podemos preguntarsenos si la TO no es más apla para vivir y expresar las dimensiones sociales, comunitarias y utópicas del cristianismo que la teolngía occidental latina, profundamente marcada por el individualismo, el racionalismo y el dualismo. En todo caso es obvio que la teologia clásica occidental es ya insuficiente para expresar las nuevas exigencias y esperanzas cristianas de una humanidad que desea caminar por sendas de justicia y libertad hacia el reino: el vino nuevo requiere odres nuevos.

\section{NOTAS}

1. Por ejemplo las discusiones sobre el hesicasmo en $\mathrm{cl}$ siglo XIV en las cuales se enfrentaron la mentalidad nominalista y esencialisıa Jel calabrés Barlaam y el pensamiento existencialista del obispo de Tesalónica Gregorio Pálamas.

2. La bibliografia sobre la TL es ya inmensa. A lo largo de estas páginas iremos citando autores y obras más representativas. Como visión sintética de conjunto puede consultarse la obra del europeo J. Ramos Regidor, Jesús y el despertar de los oprimidos, Salamanca, 1984, donde se encuentra ultcrior bibliografia.

3. V. Lossky, Theologie mystique de l'Eglise de l'Orient, Paris, 1944, H. G. Beck, Kirche und theologische Literasur im byzantinischen Reich, Munich, 1959. J. Meyendorff, Orthodoxie et Carholicile, Paris, 1965: Byzantine Theology, New York, 1974; L'Eglise Orrohodoxe hier el aujourd' hui. Paris, 1960. O. Clèment, L'Eglise Orlohodoxe, Paris, J965: Questions sur I'home, Paris, 1974; L'éssor dil Chrisfianisme oriental, Paris, 1964: La révolle de l'Esprit. Paris, 1979. S. Boulgakoff, L'Orthodoxie, Paris, 1932. L. Ouspenky, Theologie de l'icone, Paris, 1980. T. Spidklik, La spiritualite de l'Orient Chrétien, Roma, 1978. P. Evdokimov, Orrodoxia, Barcelona, 1968. J. Zizioulas, L'Etre ecclesial, Geneve, 1981.

4. Vtase V. Losski, o.c. p. 6.

5. PG 44, col. 1024.

6. PG. 44 , col. $297-430$.

7. JD. Zizioulas, Vérité el communion dans la perspective de la pensée patristique grecque, Irénikon 50 (1977), 451-510, resumido en Selecciones de Teologia, 1979, 71, 251-271.

B. G. Gutiérrez, Beber en su propio pozo, Lima, 1983; J. Sobrino, "Espiritualidad y teologia," Revisia Latinoamericana de Teologia, 1984, I, 195-224.

9. G. Gutiérrez, El Dios de la vida, Lima, 1982, 5-8.

10. Mons. O. Romero, Discurso de Lovaina, 2 de febrero de 1980.

11. J. Sobrino, Jesús en America Larina, Santander, 1982, 164-169.

12. G. Gutitrrez, Teología desde el reverso de la hisforia, Lima, 1977.

13. H. de Lubac, Exégèse médiévale, Paris, 1959-1964.

14. C. Mesters, "Flor sin defensa. Leer el evangelio en la vida," en SEDOC, Una Iglesia que nace del pueblo, Salamanca, 1979, 329-431. 
15. H. de Lubac, Corpus mis/icum. Paris, 1949, $248-277$.

16. Sobre el melondo tenligico de la Tl. puede consultarse: C. Bolf. Terologia de lo polimen, Sala-

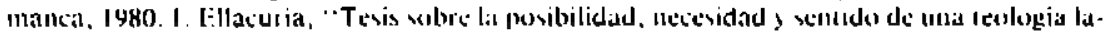
tinoamericana," in Teologia y mundo compemperámeo. Homenaje a $K$. Rohner. Madrid, 1975, 325-350. 17) PG 36.560 A.

17. PG $36.560 \mathrm{~A}$.

IB. PG 7.873.

19. Citado or O. C'lèment, Orhodoxie, Paris, 1965, p. 63.

20. I. Mejendorff. Bramme 7heolog." New York. 1974, P. 144, con mumerosas cilas de los padres oricurales en este sentido.

21. A. Soljenitsyn. Le premer cercle. ['aris, 1988, p. 346.

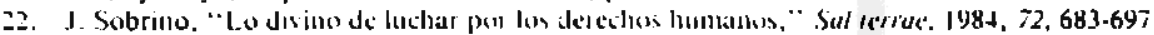

23. 1. Ellacuria "Histon icidad de la salvacion ctistiana," Re'vista Latmoumericena de Feologia. 1984. I. 5.45 .

24. AA. VV. La hacha de los dhoses. Manjuna-S. Iose de Cosla Rica. IORO.

25. V. Codina, "La cuestion de fondo en el debate sobre la leologia de la liberacion," l'aginas. 1984, 9.6-11.

26. PC; 37,181.

27. P. Evdokimos, Le Christ Ians la pemsée risse, Paris, 1950.

28. PG 59.721-724.

29. Cuando la cologia ortodoxa niega la innaculada concepción de Maria, no niega la ausencia de pecado en Maria, sino su inmortalidad, en coherencia con su intepretación del pecado original, estrechamente ligada a la muerte. La hermenéutica de los dogmas y de las a firmaciones teológicas presupone un conocimiento de las coordenadas culturales y teológicas de cada momento hisı́rico, fuera de las cuales cl dogma o cualquier afirmación tcológica resulıa incomprensible. En el actual debate sobre TL no siempre se tienen en cuenia las coordenadas sociales y culturales de donde ha nacido.

30. Véanse: L. Bofr, Jesucrisıo liberador, Sanıander, 1980. J. Sobrino, Crisılogia desde America latina, México, 1977 y Jesuis en América latina, Santander, 1983.

3I. R. Sierra Bravo, Doctrina social y económica de los Padres de la Iglesia, Madrid, 1967.

32. J. Sobrino, Jesis en America Laina, 157.206.

33. Gustavo Gutièrrez, Teología de la liberación Lima. 1971 y "Pobres y liberación en Puebla," Pdginas, 1979, 4. 1-32.

34. J. Sobrino, Jesús en América Latina, 190-195.

35. Pueblo, 282.

36. P. Evdokimov, L'Esprit Soint dans la Traditions Orthodoxe, Paris, 1969.

37. Ignace Hazim, La résurrection el /'home d'aujourd'hui, Beirul,. 1970, 30-31.

38. J. Comblin, "A Missao do Spirito Santo, "Revisıa Eclesióstica Brasileira, 1975, 35. 288-325. resumido en Selecciones de Teologia, 1977, 62, 111-126.

39. Véase el clásico estudio de K. Rahner, "Théos en el Nuevo Testamento," Escritos de Teologia, I, Madrid, 1961, 93-167, que confirma la verdad de las afirmaciones de los orientales.

40. P. Evdokimov, L'Espril Sainl dans la Tradition Orthodoxe, p. 72.

41. Véanse las sugerencias de J.C. Scanonne, "La situación de la Iglesia argentina y la imagen de Dios trino y uno," Esfudios 1970, 60, 20-22, resumido en Selecciones de Teologia, 1977, 62, $109-110$.

42. P. Evdokimov, L'Esprit Saint dans to Tradition Orthodoxe, p. 77.

43. S. Boulgakov, Orshodoxie, p. 1.

44. Ibiden, p. 5.

45. P. Evdokimov, L'art de l'icone, Paris, 1970, p. 198.

46. L. Boff, Ectesiogénesis, Santander, 1979, y Iglesia, corisma y poder, Santander, 1982. Sobre la eclesiologia de la liberación en general, puede verse: A. Quiroz, Eclesiologio en la reologia lasinoamericana de la liberación, Salamanca, 1983. V. Codina, De la modernidad a la solidaridad, Lima, 1984, 103-131.

47. I. Ellacuria, Conversión de la Iglesia al Reino de Dios, Santander, 1985.

48. Compárese los planteamientos de L. Bolf en Eclesiogénesis con los típicos de la teologia europea (H. Kung, E. Schillebeeckx). 
49. G. Múgica, Los pobres en los padres de la Iglesia, Lima, 1978. J. Leuridan, Justicia y explotación ent la tradición cristiana antigua, Lima, 1980.

50. E. Dussel. El episcopado latinoamericano y la hiheración de los pobres. Míxico, 1979. Víasc tambićn Puebla, 8-9.

51. Juan Pablo Il, Discurso inaugural de Puebla. 111, 4; AAS, LXXI, p. 200: Puebla 975, 1224, 1281.

52. 1. Ellacuria, Conversion de la lglesia al Reino de Dios. p. 279-292.

53. A. Acerbi, Due ecclesiologie. Ecclesiologia giuridica ed ecclesiologia di communione nella Lumen Gentium, Bologna, 1975.

54. I. Ellacuria, Conversión de la lglesia al Reino de Dios. H. Groencil, "Na !greja. quem i a Povo?" Revisia Eclesicistica Brasileira, 1979, 39, 195-221, resumido cil Selecciones de Teologia, 1981, 77, 63-67.

55. De parte de la teologia de la liberación pucden verse: Equipo SELADOC, Religiosidad popuIar, Salamanca, 1976. D. Irarrámaval, "Medellin, Puebla: religiosiclad popular," Póginas. $1979,4,19-49$.

S6. I. Hausherr, "Les grandes courants de la spiritualité Orientale," Orientalia Christianu Periodica, 1935, I, 114-138.

57. F. Vandenbroucke, La Spiritualicé dil Mojen Age, Paris, 1961.

58. P. Evdokimov, Le äges de la vie spirituelle, Paris, 1964.

59. I. Hausherr, Penthos, Roma, 1944.

60. O. Clement, Orthodoxie, p. 122.

61. G. Gutièrrez, Beber en su propio pozo. p. 59-63.

62. V. Codina, "Teologia del clamor popular," Revisla Larinoamericano de Teologia, 1984, 3. p. 309-328.

63. J. Sobrino. "La vida religiosa en el tercer mundo," en Resurrección de la ierdadera Iglesia, Santander, 1981, 314-349.

64. N. Berdiaev, Les sources er le sens du communisme russe. Paris, 1963. ¿Es puramente casual que J.L. Segundo, uno de los iniciadores de la TL haya hecho su tesis docioral sobre N. Berdiaev?

65. P. Evdokimov, "Eglise et Societe," Consacts, 1967, 59-60, 190-231.

66. P. Casaldáliga, "El pan de cada dia," en Fuego y ceniza al viento, Satander, 1984, 81-82.

67. V. Codina, "Paul Evdokimov. Una teologia de la transfiguración," en Teología y experiencia espirimal, Santander, 1977, 143-196. 